\title{
Mecanismos de encapsulación nominal en la prensa informativa: estudio contrastivo polaco-español
}

\section{Mechanisms of nominal encapsulation in the informative press. A Polish-Spanish contrastive study}

\author{
Janusz Bień \\ Universidad Católica de Lublin Juan Pablo II \\ helguera@wp.pl
}

\begin{abstract}
Nominal encapsulators, also referred to by other terms coined in the Spanish tradition (discursive labels), are textual cohesion devices, frequently used in journalistic discourse to condense and summarize the predicative contents of a sentence or a textual sequence. These nominal units (nouns or syntagms) can synthesize texts of different length or even refer to discontinuous fragments. Apart from performing this very basic function founded on the discursive economy of the journalistic genre, the nominal encapsulators allow the author to recategorize the content of the encapsulated segment through different evaluative modifiers and therefore to obtain either a negative or a positive perception of the message by the reader. Given an apparent lack of research on the subject on encapsulation devoted to more than one language, our purpose is to carry out a contrastive analysis of the said phenomenon in Spanish and Polish in order to juxtapose the values and the frequency of usage of encapsulators with certain characteristics of both languages. Some formal as well as pragmatic and semantic features of nominal devices are thus analysed, namely their encapsulating mechanism, their degree of modification and some of their discursive functions.
\end{abstract}

Keywords: nominal encapsulation, cohesion, discourse labels, journalistic discourse

\section{A MODO DE INTRODUCCIÓN}

La encapsulación nominal y particularmente sus distintos valores discursivos constituyen un tema relativamente reciente tanto en la lingüística española como en la tradición europea. Los elementos encapsuladores reciben análisis variados según 
sus funciones que desempeñan en el plano de la cohesión textual y que radican principalmente en su fuerza fórica. No obstante, pese a un crecimiento notable del interés que se le brinda al fenómeno en cuestión, sobre todo en el marco de los llamados discursos específicos, se encuentran con mucha dificultad trabajos de índole contrastiva. A este respecto, son excepcionales dos estudios que nos sirven de referencia aquí: Abad Serna (2016) que propone un análisis español-alemán y González Ruiz e Izquierdo Alegría (2013) donde se emprende un análisis multilingüe, basado en un corpus paralelo de textos parlamentarios. No tenemos conocimiento de ningún estudio de este tipo en el plano contrastivo polaco-español, hecho que justifica nuestro enfoque adoptado en el presente texto.

\section{ENCAPSULACIÓN NOMINAL - CONCEPTOS Y DEFINICIONES}

Cualquier discusión acerca del comportamiento textual de los encapsuladores radica en la bipartición entre su función primaria, la de sintetizar una secuencia textual y su capacidad de recategorizar o valorar el fragmento encapsulado. La función sintetizadora o empaquetadora de los encapsuladores (EE) es de naturaleza cohesiva y se reduce meramente a condensar alguna información predicativa aparecida en el texto. En cambio, la función categorizante radica en la naturaleza semántica de los EE o de sus calificativos y permite al autor etiquetar el contenido del texto condensado hasta introducir algún valor epistémico o axiológico. Los EE permiten al autor resaltar cualquier parte del texto e introducir en él alguna idea subjetiva provocando la interacción con los lectores. De este modo, se pueden convertir en una estratagema de persuasión, canalizando una percepción negativa o positiva del mensaje. Diferentes contenidos evaluativos o la valoración del grado de expectabilidad (información obvia o novedosa) que se expresan a través de la encapsulación, dependen, en primer lugar, de la relevancia informativa que se le atribuye al contenido encapsulado; véanse López Samaniego (2011: 562) o González Ruiz e Izquierdo Alegría (2013: 188). Cabe aclararse, también que los EE, a la hora de desempeñar una función evaluadora o categorizante se convierten en etiquetas discursivas (EEDD), hecho que los diferencia de otros mecanismos de encapsulación: proformas gramaticales o encapsuladores nominales propios, no evaluativos. En el ejemplo siguiente, el encapsulador sofisma se convierte en una ED puesto que aporta a la secuencia encapsulada una valoración epistémica negativa:

Por otro lado, el Primer Ministro de Italia, Silvio Berlusconi, acaba de decir que está a favor de la paz, pero que no puede compartir la responsabilidad de echarse atrás ante aquellos que amenazan nuestra seguridad, libertad y democracia. En mi opinión, con sofismas de este tipo, somos nosotros quienes ponemos en peligro nuestra libertad nuestra democracia y nuestros principios [...] (González Ruiz e Izquierdo Alegría 2013: 188; el resalte es original). 
Según varios teóricos del discurso, la encapsulación asume tres (meta)funciones del lenguaje establecidas por Halliday (1975: 148 y ss.) en el marco de su lingüística sistémico-funcional:

- función ideativa, pues los EE poseen un significado conceptual que se reconstruye en el cuerpo del texto,

- función interpersonal del lenguaje: la información encapsulada activa la memoria discursiva del lector (concepto que exponemos más adelante),

- función estructural, pues los EE jerarquizan la información textual como lo hacen otros mecanismos de cohesión (González Ruiz 2009).

A la hora de resaltar las posibles funciones textuales de los EE, cabe recordar el llamado principio de dependencia interpretativa, uno de los fundamentos conceptuales del mecanismo en cuestión, indicado y analizado por González Ruiz (2009: 251) "según el cual en toda relación fórica de remisión textual, sea anafórica o catafórica, hay una expresión sin autonomía semántica o referencial que necesita del contenido de otra expresión para saturarse o llenarse de significado". Es de notar que a la diferencia de mecanismos pronominales de cohesión, con los EE se asiste a una transferencia subjetiva de rasgos léxicos de la secuencia sintetizada, así que la selección de elementos encapsuladores por parte del autor depende tan solo parcialmente del contexto discursivo.

La falta de autonomía semántica de los EE está puesta de relieve también en los estudios ingleses, en que se usa generalmente la etiqueta label with necessity of lexicalisation (cf. Hunston y Francis 1999: 186). Por otra parte, el mismo concepto que recuerda el principio de dependencia interpretativa se detecta igualmente en algunos trabajos de la tradición italiana. De hecho, Borreguero (2006: 76) advierte que "no existen sintagmas nominales que sean encapsuladores intrínsecos, sino que un sintagma nominal puede llegar a funcionar como encapsulador en un texto determinado si se dan ciertas condiciones, pero en ningún caso se puede determinar fuera de contexto si un sintagma nominal es un encapsulador o no lo es".

Abad Serna (2016: 27) afirma que los EE pueden referir a una determinada entidad proposicional que forma parte de la llamada memoria discursiva y que el receptor debería inferir a partir de algún índice textual. Así pues, la memoria discursiva se activa cuando no aparece un antecedente textual propiamente dicho, un fragmento directamente encapsulado, sino que el lector ha de reconstruir su sentido a partir del contexto y conocimiento del mundo. Algunos autores han llamado esta identificación del antecedente de los EE "una labor 'constructiva' por parte del intérprete" en la que entran en juego procedimientos cognitivos que "construyen o establecen el referente de las EEDD" Conte (1996: 2). En el ejemplo que citamos, el sustantivo atentado no es un verdadero empaquetador de la secuencia oracional que le precede sino que asume la función activadora:

El oficial de distrito de la Policía de Hangu, Iftikhar Ahmad, ha confirmado al diario The News que el suicida llevaba seis kilos de explosivos adosados a su cuerpo. El atentado 
fue reivindicado el mismo día por el grupo islamista Lashkar-ejhangvi (El País 10.01.2014, citado por Abad Serna (2016: 27); el atentado - EEDD, secuencia subrayada activador de la memoria discursiva).

En relación con la función categorizante y con el potencial evaluativo de las EEDD, los lingüistas resaltan también su poder retórico-argumentativo. En este sentido se ha insistido en explicar su función interpersonal. Tal y como apunta Mur Dueñas (2003-2004: 138) son índices propuestos por el emisor para interpretar el fragmento sintetizado. La semántica de la etiqueta discursiva seleccionada (y por cierto, la de sus modificadores) da cuenta de la actitud, el tipo del compromiso o el punto de vista que debería manifestar el locutor respecto de dicha información.

En lo que se refiere al potencial argumentativo de las EEDD, algunos investigadores han intuido que su eficacia persuasiva y su efecto objetivador residen en las características semántico-referenciales de los elementos nominales de la lengua que tienden a presentar las informaciones como consabidas, que no son objeto de la aserción y, por tanto, se presentan con validez general, como evidentes y no susceptibles de ser discutidas (v. González Ruiz (2010: 137) y González Ruiz e Izquierdo Alegría (2013: 188)). Este carácter retórico de no aserción y su potencial objetivador radica en la abstracción de los EE, pero es propio del estilo nominal en general. Las formas nominales conllevan informaciones encerradas desde el punto de vista dialéctico, informaciones que no son objetos de aserción posterior en el texto.

\section{PROBLEMAS TERMINOLÓGICOS Y NOCIONALES}

Los encapsuladores nominales han recibido numerosas apelaciones, sobre todo en los trabajos de la tradición española, que varían según tipo y nivel de análisis. Algunas de ellas indican directamente su estatus nominal: sustantivos envoltorio, nombres metalingüisticos e inespecíficos, nombres señaladores, nombres generales, hiperónimos. Cabe añadirse que la lingüística inglesa ha forjado el término shell nouns (Hunston y Francis 1999) que por muy exótico que parezca se asemeja léxicamente a los calificativos españoles que acaban de citarse. No obstante, es el funcionamiento discursivo y las implicaciones en el plano de la pragmática lingüística que prevalecen a la hora de establecer las denominaciones más ajustadas de los EE: etiquetas discursivas, etiquetas retrospectivas y etiquetas prospectivas, etc. Algunas nociones aluden directamente a la función anafórica de los encapsuladores, pues, aparte de la más usual y clásica anáfora conceptual circulan en la literatura especializada las expresiones siguientes: anáfora compleja, anáfora recapitulativa o anáfora resumitiva (Moirand 1975), nombres anafóricos o encapsulación anafórica ${ }^{1}$.

\footnotetext{
${ }^{1}$ Véase un repaso completo en Abad Serna (2016: 22).
} 
Huelga añadirse al final que, vista la escasez de estudios contrastivos sobre el asunto, en la lingüística polaca no existe ningún debate terminológico relacionado con el fenómeno de encapsulación.

\section{CLASES LÉXICAS DE LOS SUSTANTIVOS ENCAPSULADORES}

En líneas generales, la capacidad sintetizadora es propia de todos los elementos nominales (o pronominales), pero en particular, de una clase de sustantivos de alto grado de genericidad. De hecho, proformas léxicas o nombres generales son unos de los términos que designan con frecuencia los sustantivos encapsuladores. Concretamente, los nombres de carga semántica diluida que se emplean para conseguir este efecto fórico de encapsulación son los siguientes: hecho, lugar, circunstancia, acontecimiento, estado, operación, cuestión, decisión, idea, acción, actuación, caso, afirmación, declaración, etc. Quedan excluidos, por ejemplo, los sustantivos clásicos con semántica muy compacta que designan entidades físicas (ciudad, gobierno, periódico, etc.).

Todos los vocablos enumerados pueden funcionar perfectamente como hiperónimos frente a conceptos más concretos y particulares que se reencuentran en el cuerpo de la noticia periodística. Borreguero (2006: 83) distingue, en realidad, dos tipos de elementos encapsuladores de los que se sirve el autor para sintetizar y luego recategorizar un fragmento de texto: sustantivos de un tipo léxico concreto y nombres (o sintagmas) polisémicos cuyos ejemplos acaban de citarse. La división nos parece justa en la medida en que el primero sea un sustantivo formalmente relacionado con un verbo que aparece obligatoriamente en la parte encapsulada, y el segundo, como hemos observado, puede originar un amplio abanico de referencias, vista su semántica muy general.

En algunas fuentes dedicadas al problema, se recuerda que las secuencias textuales se encapsulan mediante entidades que corresponden siempre al segundo o tercer orden de la clasificación ontológica llevada a cabo por Lyons (1977: 387 y ss.), eso quiere decir a los eventos (accidente, desastre), acontecimientos (suceso, actuación), procesos, estados (situación), actitudes, actos de habla (explicación, idea) o conceptos y proposiciones (condición, problema, afirmación), etc. (cf. López Samaniego 2015: 456-457). Efectivamente, en la tradición inglesa los mencionados arriba shell nouns se dividen en 2 grupos léxicos que contienen únicamente entidades abstractas por definición: "nouns which refer to something that is written or spoken" y "nouns which refer to beliefs, ideas, wishes and thought processes"; Hunston y Francis (1999: 186).

\section{ENCAPSULACIÓN COMO MECANISMO DE COHESIÓN LÉXICA}

Por su naturaleza fórica los EE contribuyen a la organización informativa del texto como ocurre con otros elementos léxicos o gramaticales que pueden desempeñar una función cohesiva. Recordemos que se distinguen tres mecanismos funda- 
mentales de cohesión léxica: repetición, reiteración y asociación. La mayor fuerza cohesiva se manifiesta en el caso de la repetición "que implica una coincidencia de referente, sentido y forma entre el antecedente y la marca de referencia" (Cuenca 2010: 49). La repetición léxica de un antecedente textual puede ser total o parcial. En el primer caso se trata de la reproducción literal de la forma, no obstante el segundo mecanismo es mucho más natural y desde el punto de vista de la organización textual es el más explotado por los autores de textos.

A la diferencia del primer procedimiento, la reiteración no implica necesariamente la repetición de la misma forma del antecedente, sino que puede realizarse mediante un hiperónimo, hipónimo o sinónimo:

Los padres desean que sus hijos reciban la mejor educación posible, y es en los meses de marzo y abril cuando deben afrontar esta elección: ¿matricularles en un centro público o en uno privado? Para elegir bien, los progenitores deben tener en cuenta factores como el proyecto educativo, la calidad de la enseñanza, las instalaciones, los servicios al alumno o las actividades extraescolares (Cuenca 2010: 50).

Es en esta línea de las estrategias de cohesión se sitúa ciertamente la encapsulación, apelando al uso de nombres con semántica muy general que recuerdan las características de los elementos de reiteración. La diferencia entre ambos mecanismos reside en que el antecedente del encapsulador (o la secuencia posterior en el caso de su función catafórica) no es un nombre simple o sintagma nominal sino una secuencia textual más o menos extensa. De hecho, la encapsulación puede clasificarse como un subtipo funcional de la reiteración implicando una relación semántica que no solo mantiene la referencia con el antecedente, sino que permite caracterizar la entidad referida objetivamente o subjetivamente mediante sinónimos, hipónimos, hiperónimos, etc. ${ }^{2}$.

La última técnica de cohesión léxica es la asociación que se aleja de las precedentes tanto en el plano formal como conceptual. Normalmente, los elementos de asociación, no poseen la misma forma (no se realizan por lexemas idénticos) ni tampoco comparten el mismo referente con los antecedentes, pero sí, pertenecen al mismo campo léxico y refieren al mismo tópico del texto. Para dar un ejemplo ilustrativo de esta categoría de cohesión los autores se sirven con frecuencia de textos de receta de cocina en los que alrededor de un tema central giran elementos semánticamente relacionados que designan ingredientes, platos o actividades culinarias. Este tipo de texto refiere al llamado saber enciclopédico del lector, fenómeno que recuerda la activación de su memoria discursiva, que evocamos en otras líneas del presente trabajo.

\footnotetext{
${ }^{2}$ Los mecanismos de cohesión léxica alternan con los mecanismos gramaticales, como anáfora o catáfora pronominales, que contribuyen tanto a la cohesión como a la coherencia comunicativa del texto; su análisis excede, sin embargo, el marco y la temática del presente estudio.
} 
Resumiendo este subapartado, nos parece conveniente recurrir a un ejemplo que ilustre de la mejor manera posible las tres relaciones de cohesión léxica:

La policía de Rusia asciende a capitán a Miss Universo.

Además de los numerosos regalos recibidos, agasajos, contratos y una beca para estudiar cine y televisión en Nueva York, la teniente de la policía, Oxana Fédorova, la mujer más bella del mundo, ha recibido un importante premio de sus superiores. Por ganar el concurso de Miss Universo, Oxana, que tiene 24 años y 1,80 de estatura ha sido ascendida al rango de capitán. El ministerio del interior ruso abonará a la oficial de la policía su sueldo íntegro durante todo el año en el que se dedicará a sus nuevas tareas como Miss Universo ${ }^{3}$ (Diario de Navarra, 1.06.2002, en Cuenca (2010: 47)).

Así pues, partiendo del antecedente nominal exacto Miss Universo, somos capaces, según se ha dicho, distinguir la repetición (parcial) del nombre de la policía con el nombre propio Oxana. La reiteración se realiza mediante el sintagma oficial de la policía respecto al antecedente teniente de la policía cuando el primero actúa como hiperónimo de este. Finalmente, la asociación, se establece por ejemplo entre las siguientes palabras: premio, cine, televisión, concurso, Miss universo que mantienen entre sí una relación temática y requieren del lector ciertos conocimientos del mundo exterior.

\section{ANÁLISIS CONTRASTIVO DE LOS DATOS EMPÍRICOS}

Aunque los estudios dedicados a la encapsulación que abarquen dos o más lenguas son escasos, las pautas que pueden motivar un análisis contrastivo del fenómeno son realmente numerosas. De hecho, podemos enumerar algunas cuestiones típicamente formales y otras, analizables tan solo en el plano discursivo-pragmático que pueden ser objeto de investigación polaco-española:

- frecuencia de los EE,

- tipo léxico o formal de los EE,

- calificación y modificación de los EE,

- extensión y relevancia discursiva de los segmentos encapsulados,

- dirección de la encapsulación (EE anafóricos vs EE catafóricos),

- aporte informativo (EE temáticos vs EE remáticos),

- tipo de mecanismo encapsulador: proforma léxica, anáfora conceptual o etiqueta discursiva (EEDD),

- valoración de los hechos descritos en el fragmento encapsulado (positiva, neutra o negativa),

- valores categorizantes: epistémicos, axiológicos, deónticos u otros.

\footnotetext{
${ }^{3}$ Diario de Navarra, 1.06.2002, citado por Cuenca (2010: 47); el resalte es original.
} 
Puesto que el objetivo del presente texto, de marco formal muy limitado, es dar una visión preliminar de los problemas contrastivos relacionados con la encapsulación, hemos optado por abordar cuestiones numéricamente medibles, que pueden censarse formalmente en el corpus. Siguiendo nuestro enfoque, en primer lugar, nos gustaría dar cuenta de las frecuencias de los EE, luego de su modificación y en último lugar del tipo de valoración que confieren al texto encapsulado.

Nuestro corpus de referencia de tipo comparable y bilingüe, está anotado manualmente, y consta de 30000 palabras gráficas. Se trata, de una muestra representativa y diversificada del discurso periodístico: prensa de información, prensa deportiva; prensa nacional, prensa local ${ }^{4}$. Su constitución cumple con todos los parámetros requeridos por los teóricos de la lingüística del corpus, antes de todo con la representatividad temática y el mismo tamaño de las muestras en ambas lenguas. En realidad, los textos en dos o varias lenguas pertenecientes a un mismo corpus comparable han de compartir cinco características siguientes: tema, periodo, estilo, tipo de publicación y medio de transmisión y es el caso de los textos que se someten al análisis aquí (cf. Lewandowska-Tomaszczyk 2005: 52-53).

En cuanto a la frecuencia cruda de los EE de todo tipo, hemos notado una ligera ventaja del español sobre el polaco: 152 ocurrencias sobre 30000 formas $(5,07$ por mil de promedio) frente a los 123 elementos de encapsulación en polaco, censados en la muestra de la misma extensión textual.

En el plano de la modificación, la diferencia entre ambas lenguas es sensible: el número de los EE que reciben alguna modificación (y en consecuencia se convierten casi siempre en etiquetas discursivas) es dos veces superior en español. Esta tendencia puede estar motivada por distintas razones que se escapan de la simple perspectiva formal o tipológica. Tal vez se trate de un carácter peculiar de la prensa española (expresividad o agresividad) o incluso de alguna actitud personal de los periodistas españoles.

Tabla 1. Modificación de los EE en español y en polaco

\begin{tabular}{|c|c|c|}
\hline & con modificación & sin modificación \\
\hline EE españoles & $40,2 \%$ & $59,8 \%$ \\
\hline EE polacos & $22,76 \%$ & $77,24 \%$ \\
\hline
\end{tabular}

En lo que respecta a la valoración, las divergencias entre ambas lenguas parecen ser menos notables que en el caso de la modificación. Este hecho radica tal vez en la temática de los textos de información que ha de ser paralela, pese a que los dos subcorpus son de tipo comparable. La tabla siguiente resume nuestro censo.

\footnotetext{
${ }^{4} \mathrm{El}$ marco reducido del presente texto no nos permite citar toda la bibliografía referente a los textos del corpus (en total más de 40 referencias); la citamos en integridad en otra fuente: Bień (2013: 326-329).
} 
Tabla 2. Los EE en español y en polaco: tipos de valoración

\begin{tabular}{|l|c|c|c|}
\hline \multicolumn{1}{|c|}{ valoración } & positiva & negativa & neutra o sin valoración \\
\hline EE españoles & $17,76 \%$ & $11,84 \%$ & $70,39 \%$ \\
\hline EE polacos & $9,76 \%$ & $8,14 \%$ & $82,11 \%$ \\
\hline
\end{tabular}

A continuación, citamos finalmente algunos ejemplos modelos que ilustren dos tipos de modificación clave. En el primero de ellos asistimos a una modificación con valoración negativa, ya que el autor menosprecia la idea presentada en el antecedente textual:

Nie możemy nikogo wysłać. I na jakiej podstawie mielibyśmy to robić? Najlepiej niech pan czeka do godz. 18, wtedy zaczna prace przychodnie nocne, one maja samochód i stamtąd ktoś na pewno do pana przyjedzie - usłyszał w odpowiedzi. Było to jakieś rozwiqzanie, jednak pana Adama martwiło, że...” (K.4.1.3.) (Bień 2013: 328).

El siguiente y el último ejemplo que alegamos en el presente trabajo, representa la encapsulación realizada por una etiqueta discursiva de valoración positiva, expresada de manera explícita por un calificativo, aumentado por la presencia de un adverbio de intensidad:

Od kilku miesięcy mówi się, że jako kolejne na świdnickim lotnisku pojawią się Eurolot i Lufthansa. Pierwsza linia miałaby obsługiwać loty krajowe (najbardziej prawdopodobne kierunki to Gdańsk, Kraków i Szczecin), a druga - zabierać pasażerów do Frankfurtu nad Menem, skạd dosteppne byłyby już połaczenia z całym światem. Gdyby te zapowiedzi się spełniły, to byłaby bardzo dobra wiadomość (K.4.2.1.) (Bień 2013: 328).

\section{OBSERVACIONES FINALES}

Como se ha podido observar, la frecuencia de los EE es ligeramente más alta en la prensa informativa española que en la prensa polaca. La diferencia no parece ser muy relevante desde el punto de vista científico, no obstante, en cierta medida, va en contra de las consideraciones de índole tipológica que oponen el léxico genérico de las lenguas románicas al léxico específico de las lenguas eslavas. En vista de corroborar esta tendencia se requiere un estudio más global, basado en fuentes de datos electrónicas.

Los datos concernientes a la aparición de modificadores en ambas lenguas confirman la función primaria, sintetizadora, de este tipo de elementos lingüísticos, en detrimento de su función valorativa, que consideramos como su característica secundaria. Las diferencias existentes entre los encapsuladores españoles y polacos en el plano de la valoración se deben, sin duda, a factores de diversa índole (también a factores extralingüísticos): carácter del mensaje, tipo de prensa, estilo personal del periodista, etc. 


\section{BIBLIOGRAFÍA}

Abad Serna, S. (2015). Estudio contrastivo del funcionamiento semántico de los encapsuladores nominales en la prensa española y alemana. De la anáfora a la catáfora conceptual (tesis doctoral). Madrid: Universidad Autónoma de Madrid.

Abad Serna, S. (2016). Funcionamiento semántico de los encapsuladores nominales en la prensa informativa: un análisis contrastivo. In R. González Ruiz, A. Jimeno Zuazu, C. Llamas Saíz (eds.), Lingüística y pragmática (pp. 21-37). Madrid: Síntesis.

Bień, J. (2013). El estilo nominal en español y en polaco. Lublin: Polihymnia.

Borregero, M. (2006). Naturaleza y función de los encapsuladores en los textos informativamente densos (la noticia periodística). Cuadernos de Filología Italiana, 13, 73-95.

Conte, A. (1996). Anaphoric encapsulation. Belgian Journal of Linguistics, 10, 1-11. DOI: https://doi.org/10.1075/bjl.10.02con.

Cuenca, M.J. (2010). Gramática del texto. Madrid: Arco Libros.

González Ruiz, R. (2009). Algunas notas en torno a un mecanismo de cohesión textual: la anáfora conceptual. In M.A. Penas, R. Gónzalez Ruiz (eds.), Estudios sobre el texto. Nuevos enfoques y propuestas (pp. 247-278). Frankfurt: Peter Lang.

González Ruiz, R. (2010). Gramática y discurso: nominalización y construcción discursiva en las noticias periodísticas. In C. Martínez Pasamar (ed.), Estrategias argumentativas en el discurso periodístico (pp. 119-146). Frankfurt: Peter Lang.

González Ruiz, R., Izquierdo Alegría, D. (2013). Encapsulación y etiquetas discursivas en el discurso parlamentario: función argumentativa a partir de un corpus paralelo. Oralia, 16, 185-219.

Halliday, M.A.K. (1975). Estructura y función del lenguaje. In J. Lyons (ed.), Nuevos horizontes de la lingüistica (pp. 145-173). Madrid: Alianza.

Hunston, S., Francis, G. (1999). Pattern Grammar. A corpus-driven approach to the lexical grammar of English. Amsterdam/Philadelphia: John Benjamins.

Lewandowska-Tomaszczyk, B. (2005). Podstawy językoznawstwa korpusowego. Łódź: Wydawnictwo Uniwersytetu Łódzkiego.

López Samaniego, A. (2011). La categorización de entidades del discurso en la escritura profesional. Las etiquetas discursivas como mecanismo de cohesión léxica (tesis doctoral). Barcelona: Universitat de Barcelona.

López Samaniego, A. (2015). Etiquetas discursivas, hiperónimos y encapsuladores: una propuesta de clasificación de las relaciones de cohesión referencial. RILCE, 31.2, 435-462.

Lyons, J. (1977). Semantics $1 \& 2$. Cambridge: Cambridge University Press.

Moirand, S. (1975). Le rôle anaphorique de la nominalisation dans la presse écrite. Langue française, 28, 60-78. DOI: 10.3406/lfr.1975.6091.

Mur Dueñas, P. (2003-2004). Analysing stance in American and Spanish Business Management ras: the case of sentence-initial retrospective labels. Journal of English Studies, 4, 137-154. 